\title{
Precocious puberty secondary to a mixed germ cell-sex cord-stromal tumor associated with an ovarian yolk sac tumor: a case report
}

\author{
Kotb Abbass Metwalley ${ }^{1 *}$, Dalia Ahmed Elsers ${ }^{2}$, Hekma Saad Farghaly ${ }^{1}$, Hanaa Abdel-Lateif ${ }^{1}$ and
} Mohamed Abdel-Kader ${ }^{3}$

\begin{abstract}
Introduction: Ovarian tumors are the least common cause of sexual precocity in girls. Mixed germ cell-sex cord-stromal tumors associated with a yolk sac tumor of the ovary are rare neoplasms, of which only a small number of well-documented cases have been described so far. Here, we report precocious puberty in a four-year-old Egyptian girl caused by a mixed germ cell-sex cord-stromal tumor associated with a yolk sac tumor of the ovary.

Case presentation: A four-year-old Egyptian girl was referred to our pediatric endocrinology unit for evaluation of bilateral breast budding, pubic hair and vaginal bleeding. On examination, we found that her breast enlargement and pubic hair were compatible with Tanner III. A thorough workup revealed a large mass in her right ovary. Magnetic resonance imaging ofher brain showed that her pituitary gland was normal. A hormonal assay revealed high levels of estradiol, 280 to $375 \mathrm{pmol} / \mathrm{L}$; progesterone, $5.3 \mathrm{nmol} / \mathrm{L}$; testosterone $38.9 \mathrm{pg} / \mathrm{mL}$; and androstenedione, $4.1 \mathrm{ng} / \mathrm{mL}$. Her basal and stimulated levels of luteinizing hormone and follicle-stimulating hormone were low. Tumor markers levels were high, with a total inhibin of 1,069U/L and an alpha-fetoprotein of $987 \mathrm{\mu g} / \mathrm{L}$. Her chromosomes were normal (46XX). Our patient underwent an explorative laparotomy and a solid tumor localized to her right ovary was identified. A right salpingo-oophorectomy was performed and the histopathological diagnosis was a mixed germ cell-sex cord-stromal tumorwith a yolk sac tumor of the ovary. Postoperatively, she was started on treatment with chemotherapy. Our patient is doing well without evidence of tumor recurrence or metastasis during eight months of postoperative follow-up.
\end{abstract}

Conclusion: Although a mixed germ cell-sex cord-stromal tumor associated with a yolk sac tumor of the ovary is a rare occurrence, it should be considered in the differential diagnosis for a prepubescent girl with an abdominal mass and precocious puberty.

\section{Introduction}

Precocious puberty in girls is defined by the development of sexual characters before the age of eight years. It is usually due to the premature activation of the hypothalamic-pituitary-ovarian axis, defined as central precocious puberty (CPP) [1]. It is rarely of ovarian or adrenal origin. CPP in girls is idiopathic in the majority of cases [2]. Ovarian tumors are the least common cause of sexual precocity. Functional neoplasms of the ovary are relatively infrequent and only $5 \%$ occur before

\footnotetext{
* Correspondence: kotb72@yahoo.com

${ }^{1}$ Paediatric Endocrinology Unit, Department of Paediatrics, Faculty of Medicine, Assiut University, Assiut, Egypt

Full list of author information is available at the end of the article
}

puberty [3]. Granulosa-theca cell tumors are the most common ovarian tumors to cause precocious puberty in girls [4]. Most ovarian tumors develop from one of three sources: the germinal epithelium covering the urogenital ridge; the underlying stromal elements of the urogenital ridge; or germ cells from the yolk sac. The most common malignant germ cell tumors are dysgerminomas (48\%) and yolk-sac tumors (20\%). Approximately $10 \%$ of neoplasms are composed of a mixture of different histological types [5]. Tumors that contain an admixture of germ cell and sex cord-stromal derivation include gonadoblastoma and mixed germ cell-sex cord-stromal tumor (MGCCST) -non gonadoblastoma type [6]. To the best of our knowledge, an MGCCST with a yolk sac 
tumor has not yet been described in Egypt. Here, we describe the clinical, histopathological and immunohistological findings of a case of an MGCCST with a yolk sac tumor that occurred in a four-year-old Egyptian girl presenting with precocious puberty.

\section{Case presentation}

A four-year-old Egyptian girl was referred to our pediatric endocrinology unit for evaluation of bilateral breast budding and growth of pubic hair of four months duration followed by two episodes of vaginal spotting, initially noticed two weeks prior to her presentation. Her previous medical history and birth history were unremarkable; there was no family history of endocrinological disorders or precocious puberty. At presentation, our patient was an alert, irritable child. Her height was $115 \mathrm{~cm}$ (>97th percentile) and weight $20 \mathrm{~kg}$ (90th percentile). Her vital signs were normal. She had normal ocular, thyroid and cardiorespiratory examinations and no lymphadenopathy. Her breast tissue was palpable and the contour of her nipples and areolae was equivalent to Tanner stage III breast development. Her pubic hair was coarse, pigmented and distributed over her labia majora, equivalent to Tanner stage III [7]. Inspection of her external genitalia revealed estrogenized vulval mucosa with a clear viscous discharge, and the clitoris was slightly enlarged. An abdominal mass was palpable in her suprapubic area, firm in consistency, not tender, with ill-defined borders. There was no obvious ascities.

An initial ultrasonographic study of her abdomen and pelvis revealed an enlarged uterus with prominent endometrium and $7.8 \mathrm{~cm} \times 5.2 \mathrm{~cm}$ irregular, inhomogeneous mass in the right adnexal region lying above her uterus and crossing the midline. Her left ovary, adrenals, liver, spleen and kidneys were normal. Computed tomography imaging of her abdomen and pelvis confirmed the above mentioned findings (Figure 1). Subsequent testing of her brain by magnetic resonance imaging revealed a normalsized pituitary and infundibulum with a normal posterior

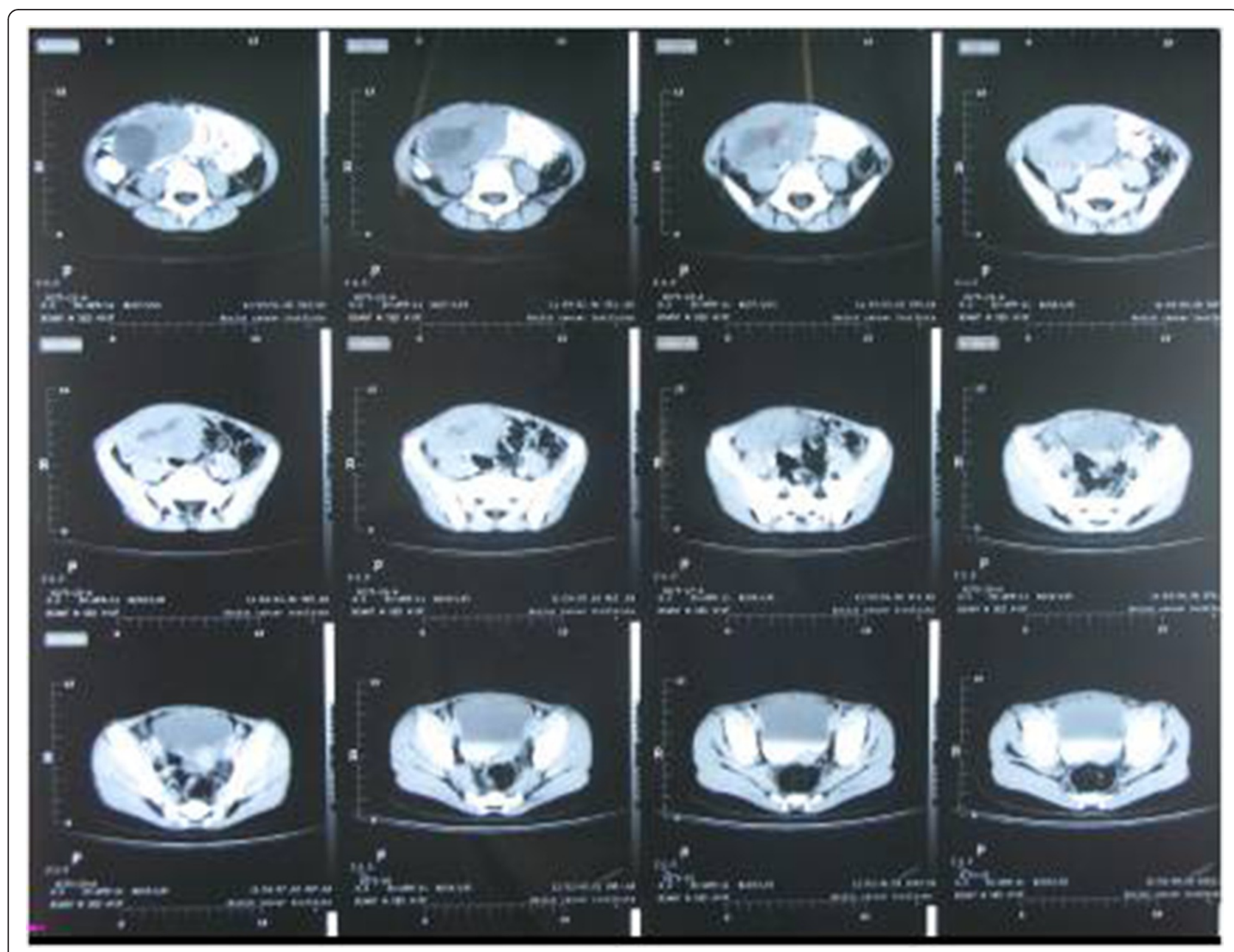

Figure 1 Computed tomography of the abdomen and pelvis shows a huge right ovarian mass. 
pituitary bright spot. An X-ray of her left hand and wrist revealed a bone age of 5 years according to female standards [8].

Laboratory values of a complete blood count and thyroid function tests were within the normal limits. Serum concentrations of estradiol were in the range of 280 to $375 \mathrm{pmol} / \mathrm{L}$ (normal $<73$ for prepubertal child); progesterone, $5.3 \mathrm{nmol} / \mathrm{L}$ (normal 0 to $1.3 \mathrm{nmol} / \mathrm{L}$ ); testosterone, $38.9 \mathrm{pg} / \mathrm{mL}$ (reference value 1 to $5.2 \mathrm{pg} / \mathrm{mL}$ ); androstenedione, $4.1 \mathrm{ng} / \mathrm{mL}$ (normal, 0.3 to $3.1 \mathrm{ng} / \mathrm{mL}$ ); and prolactin, $233 \mathrm{mIU} / \mathrm{L}$ (normal $<460 \mathrm{mIU} / \mathrm{L}$ ). Basal levels of luteinizing hormone (LH) and folliclestimulating hormone $(\mathrm{FSH})$ were low $(0.4$ and $0.7 \mathrm{IU} / \mathrm{L}$, respectively), with no change in response to stimulation by $100 \mathrm{mg}$ of LH-releasing hormone intravenously. Regarding tumor markers, the total inhibin level was $1,069 \mathrm{U} / \mathrm{L}$ (normal $<100 \mathrm{U} / \mathrm{L}$ for prepubertal child) and the alpha fetoprotein levelwas $987 \mu \mathrm{g} / \mathrm{L}$ (normal 1 to $200 \mu \mathrm{g} / \mathrm{L}$ ) while B human chorionic gonadotropin, lactic dehydrogenase and alkaline phosphatase were negative. Her chromosomes were normal (46XX). Our patient underwent explorative laparotomy one week after her initial presentation to our department; a solid tumor localized to her right ovary was identified. A right salpingo-oophorectomy was performed. Gross examination showed that the tumor mass measured about $10 \times 7 \mathrm{~cm}$ in diameter. The mass was capsulated and its outer surface was nodular with dilated congested blood vessels. The cut section was solid and with multiple cysts containing transparent thick material. The mass was firm in consistency with friable areas. Its color was yellow grayish with small dark areas of necrosis (Figure 2). The histopathological report was an MGCCST with a yolk sac tumor. The histological picture showed the presence of the yolk sac tumor and a Sertoli-Leydig

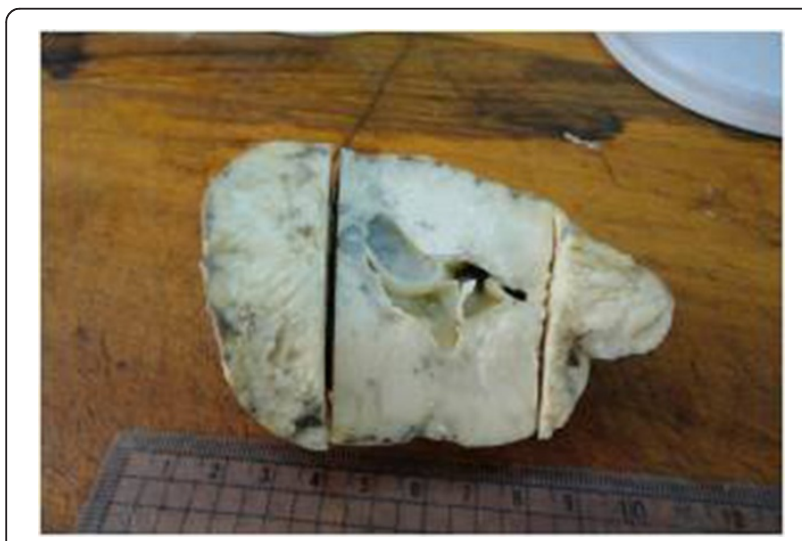

Figure 2 The cut section was solid with multiple cysts containing transparent thick material. The mass was firm in consistency with friable areas. Its color was yellow grayish with small dark areas of necrosis.

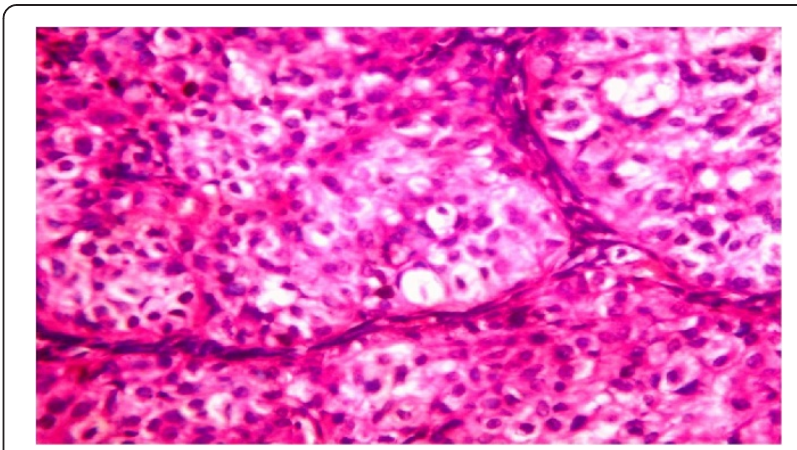

Figure 3 Hematoxylin and eosin staining $\times \mathbf{4 0}$. Large polygonal cells with abundant eosinophilic cytoplasm, and rounded hyperchromatic nuclei growing in compact masses separated by thin fibrous bands.

cell tumor with intermediate differentiation (Figures 3, 4). An immunohistochemical study of the tumor cells showed diffuse positive staining for alpha-fetoprotein (Figure 5) and focal areas of positive staining for inhibin (Figure 6).

Our patient's postoperative period course was unremarkable, although a short period of vaginal bleeding was noted a few days after surgery. Pubic hair was lost and her breasts became less prominent over the four weeks following surgery. One month after surgery, she was started on chemotherapy treatment with bleomycin, etoposide and cisplatin (BEP regimen) every three weeks for four cycles. Eight months after surgery and chemotherapy, she was tumor free on clinical examination and radiography; her estradiol and testosterone levels had decreased to $61 \mathrm{pmol} / \mathrm{L}$ and $3.1 \mathrm{pg} / \mathrm{mL}$, respectively. Our plan is to follow her up every three months for two years then every six months for five years.

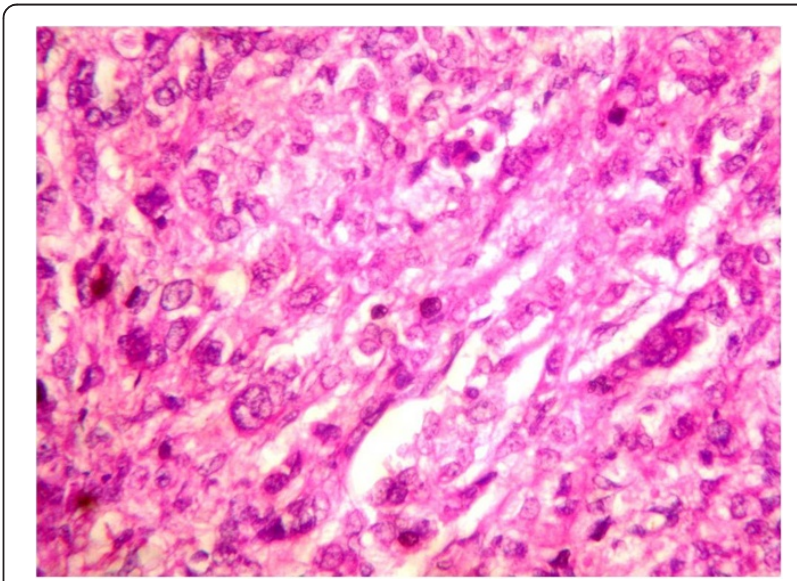

Figure 4 Hematoxylin and eosin staining $\times \mathbf{4 0}$. Primitive tumor cells with vacuolated cytoplasm. Nuclei are rounded and hyperchromatic, with prominent nucleoli. 


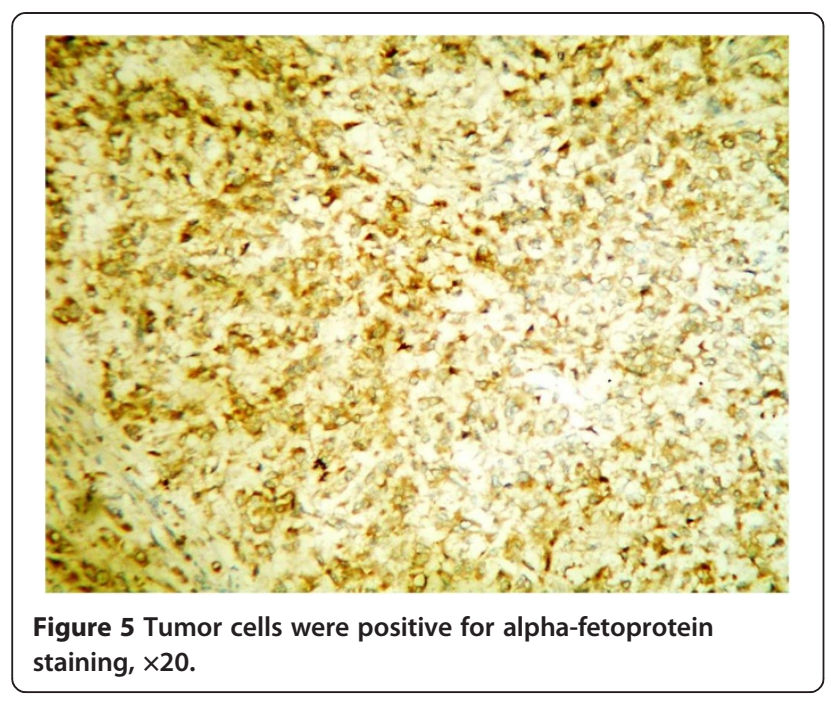

\section{Discussion}

Children with precocious puberty may be stressed because of physical and hormonal changes they are too young to understand. Going through puberty early can also be difficult for a child emotionally and socially. Girls with precocious puberty may be confused or embarrassed about physical changes, such as getting their periods or having enlarged breasts well before any of their peers. Not only that, but precocious puberty could cause the child to become an object of adult sexual interest [9]. Idiopathic CPP carries no increased risk of mortality however, distinguishing between children with idiopathic CPP and rare patients with a central nervous system, adrenal or ovarian tumor is important because the latter group may be at risk for tumor-related complications [10].

Our index case presented with a typical picture suggestive of idiopathic CPP with maintenance of the

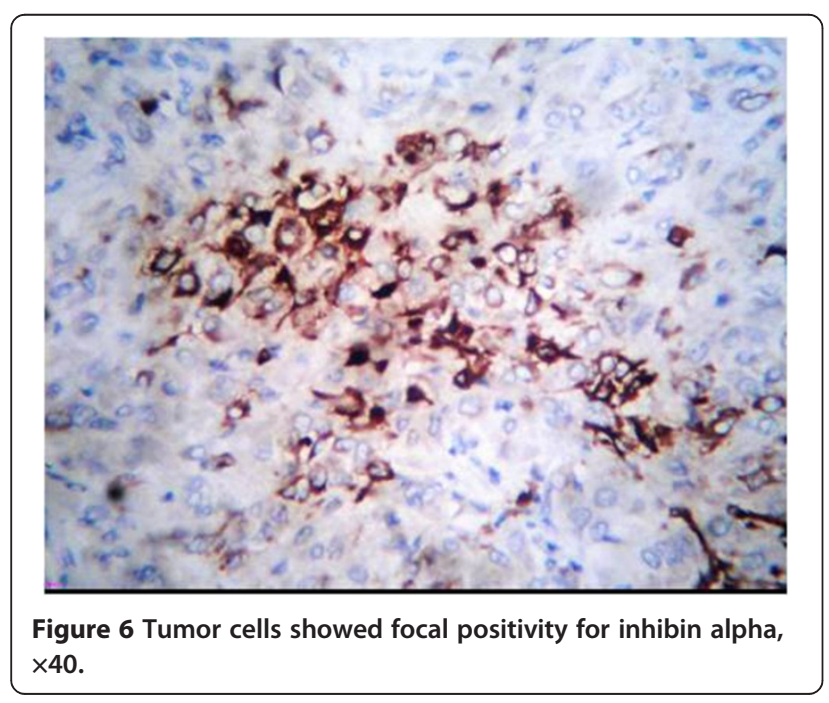

harmony (consonance) of normal puberty, that is, breast and pubic hair development, vaginal bleeding, growth acceleration and normal magnetic resonance imaging of the brain. But, the presence of an ovarian mass that was confirmed by computed tomography and low levels of FSH and $\mathrm{LH}$ pointed to an ovarian tumor as the sole cause of her precocious puberty. Her advanced bone age and accelerated height were seen because of tumor-derived estradiol. Advanced bone age, especially if it has progressed beyond the height age, serves as a nonspecific biomarker of abnormal sex steroid production [11].

The endocrine effects of the tumor on our patient were probably dependent upon the stromal components and proportions of different elements. Tumors containing both Sertoli and Leydig cells have variable effects, depending partly upon the proportion of these tumor elements and the degree of histologic differentiation. Signs of androgen excess or overt virilization occur in about half of patients with Sertoli-Leydig cell tumors. As with the pure Leydig cell tumors, estrogenic manifestations also occur. Patients with SertoliLeydig cell tumors who have defeminizing or virilizing clinical signs invariably have elevated blood testosterone levels [12]. In addition to testosterone, plasma androstenedione and, less commonly, dehydroepiandrosterone, are occasionally elevated [13]. Focal immunohistochemical positivity for inhibin confirmed the presence of the sex cord-stromal element. Total inhibin is a sensitive immunohistochemical marker of ovarian sex cord-stromal tumors [14]. The high levels of estrogen account for the breast development observed in this child and the build-up of the endometrium [15]. We presume, based on the elevated serum level of progesterone, that our patient's tumor was intermittently releasing progesterone, causing her vaginal bleeding [16]. The development of pubic hair may be accounted for by the combination of elevated testosterone, androstenedione and estrogen levels that were most likely derived from the tumor [15].

An MGCCST with a yolk sac tumor of the ovary should be differentiated clinically and pathologically from a gonadoblastoma, described by Talerman in 1972 $[17,18]$. An MGCCST with a yolk sac tumor of the ovary is very rare and there have been no reported cases in Egypt. Most cases are found in infants and children younger than 10 years, but rare cases occur in adults [19]. By comparison, a gonadoblastoma is a well-recognized tumor that occurs almost exclusively in a patient with abnormal gonadal development and a karyotype containing Y-chromosome material [20]. The prognosis of MGCCST with a yolk sac tumor of the ovary is dependent on the response to therapy of the yolk sac tumor as well as other components [21]. 


\section{Conclusion}

Although in most of girls with precocious puberty, the etiology is idiopathic, MGCCST with a yolk sac tumor of the ovary should be considered in the differential diagnosis for a prepubescent girl with an abdominal mass.

\section{Consent}

Written informed consent was obtained from the patient's parents for publication of this case report and any accompanying images. A copy of the written consent is available for review by the Editor-in-Chief of this journal.

\section{Abbreviations}

CPP: central precocious puberty; FSH: follicle-stimulating hormone; LH: luteinizing hormone; MGCCST: mixed germ cell-sex cord-stromal tumor.

\section{Competing interests}

The authors declare that they have no competing interests.

\section{Author details}

'Paediatric Endocrinology Unit, Department of Paediatrics, Faculty of Medicine, Assiut University, Assiut, Egypt. ${ }^{2}$ Department of Pathology, Faculty of Medicine, Assiut University, Assiut, Egypt. ${ }^{3}$ Department of Pediatric Surgery, Faculty of Medicine, Assiut University, Assiut, Egypt.

\section{Authors' contributions}

KA carried out the patient diagnosis, investigation, follow-up, management and writing of the manuscript. DS carried out the histopathological diagnosis and writing of the manuscript. HS carried out the patient diagnosis, followup, management and writing of the manuscript. HA carried out the patient diagnosis and follow-up. MA carried out the excision of the tumor. All authors read and approved the final manuscript.

Received: 14 February 2012 Accepted: 26 June 2012

Published: 26 June 2012

\section{References}

1. Merke DP, Cutler GB Jr: Evaluation and management of precocious puberty. Arch Dis Child 1996, 75:269-271.

2. Kalfa N, Ecochard A, Patte C, Duvillard P, Audran F, Pienkowski C, Thibaud E, Brauner R, Lecointre C, Plantaz D, Guedj AM, Paris F, Baldet P, Lumbroso S, Sultan C: Activating mutations of the stimulatory g protein in juvenile ovarian granulosa cell tumors: a new prognostic factor? J Clin Endocrinol Metab 2006, 91:1842-1847.

3. Morris JMCL, Scully RE: Endocrine Pathology of the Ovary. London: Kimpton; 1958:66.

4. Fahmy JL, Kaminsky CK, Kaufman F, Nelson MD Jr, Parisi MT: The radiological approach to precociouspuberty. Br JRadiol 2000, 73:560-567.

5. Kurman RJ, Norris HJ: Malignant mixed germ cell tumors of the ovary. A clinical and pathologic analysis of 30 cases. Obstet Gynecol 1976, 48:579-589.

6. Talerman A: Germ cell tumours of the ovary, Blaustein's Pathology of the Female Genital Tract. New York: Springer Verlag; 1994:849.

7. Marshall WA, Tanner JM: Variations in pattern of pubertal changes in girls. Arch Dis Child 1969, 44:291-303.

8. Greulich WW, Pyle SI: Radiographic Atlas of Skeletal Development of the Hand and Wrist. Stanford, CA: Stanford University Press; 1959.

9. Shah KK, Laz NB, Siddique AB, Ahmed FU: Precocious puberty-a case report. TAJ 2008, 1(21):83-86.

10. Parent AS, Teliman G, Juul A, Skakkebaek NE, Toppari J, Bourguignon JP: The timing of normal puberty and the age limits of sexual precocity: variations around the world, secular trends and changes after migration. Endocr Rev 2003, 24(5):668-693.

11. Merras-Salmio L, Vettenranta K, Mottonen M, Heikinheimo M: Ovarian granulosa cell tumors in childhood. Pediatr Hematol Oncol 2002, 19(3):145-156
12. Zaloudek C, Norris HJ: Sertoli-Leydig cell tumors of the ovary. A clinicopathologic study of 64 intermediate and poorly differentiated neoplasms. Am J Surg Pathol 1984, 8:405.

13. Gutierrez S, Bermudez M, Zylberstein C, Naredo E, Illanes L, Scaglia HE: LH receptor in testosterone-producing ovarian tumor. In vivo and in vitro HCG-stimulated testosterone production. Eur I Gynaecol Oncol 1983, 4:182-191.

14. Matias-Guiu X, Pons C, Prat J: Mullerian inhibiting substance, alphainhibin, and CD99 expression in sex cord-stromal tumours and endometrioid ovarian carcinomas resembling sex cord-stromal tumours. Hum Pathol 1998, 29:840-845.

15. Sklar CA, Kaplan SL, Grumbach MM: Lack of effect of estrogens on adrenal androgen secretion in children and adolescents with a comment on estrogens and pubic hair growth. Clin Endocrinol 1981, 14:311-319.

16. Al-Timimi A, Buckley $\mathrm{CH}$, Fox H: An immunohistochemical study of the incidence and significance of sex steroid hormone binding sites in normal and neoplastic human ovarian tissue. Int J Gynaecol Pathol 1985, 4:24-41.

17. Talerman A: A mixed germ cell-sex cord stromal tumor of the ovary in a normal female infant. Obstet Gynecol 1972, 40:473-478.

18. Scully RE: Histologic typing of ovarian tumors. 2nd edition. Geneva: SpringerVerlag; 1999:35-36

19. Arroyo JG, Harris W, Laden A: Recurrent mixed germ cell-sex cord stromal tumor of the ovary in an adult. Int J Gynecol Pathol 1998, 17:281-283.

20. Scully RE: Gonadoblastoma. A review of 74 cases. Cancer 1970, 25 (6):1340-1356

21. Kawai M, Kano T, Furuhashi Y, Mizuno K, Nakashima N, Hattori SE, Kazeto S, lida S, Ohta M, Arii Y: Prognostic factors in yolk sac tumors of the ovary. A clinicopathologic analysis of 29 cases. Cancer 1991, 67:184-192.

\section{doi:10.1186/1752-1947-6-162}

Cite this article as: Metwalley et al:: Precocious puberty secondary to a mixed germ cell-sex cord-stromal tumor associated with an ovarian yolk sac tumor: a case report. Journal of Medical Case Reports 2012 6:162.

\section{Submit your next manuscript to BioMed Central and take full advantage of:}

- Convenient online submission

- Thorough peer review

- No space constraints or color figure charges

- Immediate publication on acceptance

- Inclusion in PubMed, CAS, Scopus and Google Scholar

- Research which is freely available for redistribution 